\title{
The Research of Sunshine Sports to Psychologically Healthy to Shanghai University Students
}

\author{
Kong Huang-sheng \\ Shanghai Vocational and Technical College of Agriculture and Forestry, Shanghai, China
}

\begin{abstract}
This article used self-reporting inventory, self-test questionnaire, and other methods, chose four vocational schools in Shanghai for comparing experimental study of mental health, conducted experiments on experimental group and control group, and analyzed the current mental health of young students in Shanghai. It shows that the sunshine sports could significantly improve the students' mental health. The conclusion is that carrying out sunshine sports in vocational school extensively plays an important role in promoting mental health of young people in school. But some of the vocational schools in Shanghai in carrying out sunshine sports need to be improved.

Keywords: sunshine sports, psychologically healthy, mental health effects
\end{abstract}

\section{Preface}

In recent years, taking into consideration the students with mental health problems and physical deterioration and how to improve adolescent mental qualities, good character, the possibility of dealing with crises under various pressures have been a priority. It can be seen that in China, "Hundreds of Millions of Young Students Sunshine Sports” (referred to as the sunshine sports) is a strategic initiative to strengthen youth sports and to enhance adolescent health. The purpose of this activity is to promote the atmosphere of all types of schools at all levels of physical activities on campus and full participation in the mass culture of physical exercises, and to attract the majority of young students to play on the playground, get in touch with nature, go in the sun, participate in physical exercises actively, cultivate the interest in physical exercises, and improve the physical and mental health of students. With the "sunshine sports" deepening in Shanghai middle and primary schools, it is mainly to increase sports participation, especially the young people who subject to physical and mental health, and for the purpose of improving students physical and mental health. This paper is a starting point to explore the "sunshine sports", discussing factors of mental health in Shanghai students, aiming to getting more attention to the "sunshine sports".

\section{Object and Method}

\section{Object}

This research selected 552 students from four vocational universities in Shanghai and divided them into

Kong Huang-sheng, Shanghai Vocational and Technical College of Agriculture and Forestry. 
the experimental group and the control group (experimental group: Shanghai Vocational and Technical College of Agriculture and Forestry, City College of Science and Technology; control group: Construction School, Shanghai University of Electric Power).

\section{Method and Procedure}

Before students participating in sports, the experimental group and the control group students used SCL-90, self-questionnaires to carry out the pre-test. After carrying out sports for three months, the experimental group and control group students used SCL-90, self-questionnaires again, and used psychometric statistics statistical software for data processing. The pre-test time for the experimental group is September 22, 2010, and the after-test time is December 21, 2010. The pre-test time for the control group is on September 24, 2010, and the after-test time is December 27, 2010.

The experimental group participates in the "sunshine sports” three times a week, for one to two hours each time, which lasts three months, including: track meet, basketball, martial arts, jumping rope shuttlecock kicking, physical standards, badminton, aerobics, tennis, table tennis, football, winter, long-distance running, jumping kicks, tug of war, health testing projects, and so on; while the control group has daily routine of teaching the students.

\section{Results and Analysis}

\section{Analysis of the Health Factor Between the Experimental Group and Control group Before the Experiment}

Before the start of the "sunshine sports", the author carries on mental health test uniformly between the experimental group and the control group, recycling 543 questionnaires available, 272 for experimental group, recovery rate $98.5 \%, 271$ for control groups, recovery rate $98.2 \%$.

Table 1

Before Participating in the "Sunshine Sports", Experimental Group and Control group Compared With the National Youth Norm in Mental Health SCL-90 Test

\begin{tabular}{|c|c|c|c|c|}
\hline Factor & $\begin{array}{l}\text { University student }(\mathrm{M} \pm \mathrm{D}) \\
(n=725)\end{array}$ & $\begin{array}{l}\text { National youth norm }(\mathrm{M} \pm \mathrm{D}) \\
(n=750)\end{array}$ & $T$ value & $P$ \\
\hline Body & $1.39 \pm 0.47$ & $1.34 \pm 0.46$ & 2.19 & $<0.05$ \\
\hline Force & $1.71 \pm 0.49$ & $1.69 \pm 0.50$ & 1.98 & $<0.05$ \\
\hline Relationship & $1.85 \pm 0.56$ & $1.76 \pm 0.47$ & 2.88 & $<0.01$ \\
\hline Depression & $1.68 \pm 0.42$ & $1.57 \pm 0.35$ & 2.86 & $<0.01$ \\
\hline Anxiety & $1.58 \pm 0.43$ & $1.42 \pm 0.43$ & 2.45 & $<0.01$ \\
\hline Hostility & $1.60 \pm 0.50$ & $1.50 \pm 0.52$ & 2.23 & $<0.05$ \\
\hline Terror & $1.40 \pm 0.61$ & $1.33 \pm 0.47$ & 2.20 & $<0.05$ \\
\hline Paranoid & $1.62 \pm 0.54$ & $1.52 \pm 0.60$ & 3.05 & $<0.01$ \\
\hline Psychotic & $1.51 \pm 0.47$ & $1.37 \pm 0.47$ & 3.16 & $<0.01$ \\
\hline
\end{tabular}


Table 2

Experimental Group and Control group Compared in SCL-90

\begin{tabular}{lllll}
\hline Factor & $\begin{array}{l}\text { Experimental group }(\mathrm{M} \pm \mathrm{D}) \\
(n=309)\end{array}$ & $\begin{array}{l}\text { Control group }(\mathrm{M} \pm \mathrm{D}) \\
(n=416)\end{array}$ & $T$ value & $P$ \\
\hline Body & $1.38 \pm 0.46$ & $1.39 \pm 0.45$ & 0.757 & $>0.05$ \\
Force & $1.70 \pm 0.50$ & $1.72 \pm 0.48$ & 0.748 & $>0.05$ \\
Relationship & $1.86 \pm 0.51$ & $1.85 \pm 0.48$ & 0.089 & $>0.05$ \\
Depression & $1.67 \pm 0.47$ & $1.69 \pm 0.50$ & 0.205 & $>0.05$ \\
Anxiety & $1.58 \pm 0.46$ & $1.57 \pm 0.47$ & 0.132 & $>0.05$ \\
Hostility & $1.59 \pm 0.56$ & $1.60 \pm 0.52$ & 0.264 & $>0.05$ \\
Terror & $1.40 \pm 0.52$ & $1.40 \pm 0.48$ & 0.165 & $>0.05$ \\
Paranoid & $1.63 \pm 0.52$ & $1.62 \pm 0.50$ & 0.373 & $>0.05$ \\
Psychotic & $1.50 \pm 0.47$ & $1.51 \pm 0.50$ & 0.167 & $>0.05$ \\
\hline
\end{tabular}

From Table 1, it can be seen that students in the four selected universities in Shanghai are significant different with the national youth norm in body, force and paranoia $(P<0.05)$, also have a significant difference in relationship, depression, anxiety, terror, and psychotic items $(P<0.01)$, and the choice of survey is below the national norm group in the mental health.

From Table 2, it can be seen that each factor in the experimental group and control group has no significant difference $(P>0.05)$.

\section{The Difference of Heart Health Factors Between Experimental Group and Control group After 90 Days}

From Table 3, it can be seen that after 90 days, the factor scores in force, phobia and paranoid are significantly lower in experimental group than that in control group, and the difference is significant $(P<0.05)$, so do other factors $(P<0.01)$. Throughout the experiment, the control group did not change much in factor scores.

Table 3

The Differences Between Experimental Group and Control group in SCL-90 After 30 Days Carrying out "Sunshine Sport"

\begin{tabular}{|c|c|c|c|c|}
\hline Factor & $\begin{array}{l}\text { Experimental group }(\mathrm{M} \pm \mathrm{D}) \\
(n=308)\end{array}$ & $\begin{array}{l}\text { Control group }(\mathrm{M} \pm \mathrm{D}) \\
(n=415)\end{array}$ & $T$ value & $P$ \\
\hline Body & $1.29 \pm 0.56$ & $1.38 \pm 0.50$ & 2.843 & $<0.01$ \\
\hline Force & $1.64 \pm 0.55$ & $1.70 \pm 0.57$ & 2.018 & $<0.05$ \\
\hline Relationship & $1.70 \pm 0.43$ & $1.54 \pm 0.50$ & 2.715 & $<0.01$ \\
\hline Depression & $1.46 \pm 0.54$ & $1.70 \pm 0.58$ & 3.376 & $<0.01$ \\
\hline Anxiety & $1.31 \pm 0.48$ & $1.59 \pm 0.56$ & 3.067 & $<0.01$ \\
\hline Hostility & $1.41 \pm 0.53$ & $1.63 \pm 0.55$ & 3.184 & $<0.01$ \\
\hline Terror & $1.30 \pm 0.43$ & $1.44 \pm 0.51$ & 2.335 & $<0.05$ \\
\hline Paranoid & $1.50 \pm 0.65$ & $1.62 \pm 0.31$ & 2.109 & $<0.05$ \\
\hline Psychotic & $1.38 \pm 0.37$ & $1.52 \pm 0.55$ & 3.376 & $<0.01$ \\
\hline
\end{tabular}

\section{Experimental Results}

The mental health of selected students in four vocational schools in Shanghai is significantly poorer than 
that of the national norm young people, which shows that the current level of mental health in rural areas cannot be optimistic, and there are a considerable number of students with significant psychological problems. By carrying out the "sunshine sports" in schools, young students, to a large extent, regularly release the physical and psychological pressures, regulate their anxiety, and enhance the friendship among themselves, which in the long term will help to improve their mental health. The survey shows that the implementation of the "sunshine sports" community in the current environment, more schools just a mere formality, failed to take effective measures to attract more students out of class, out of the network, adding to the sports teams.

\section{Conclusions}

\section{Human Intervention Can Achieve Good Results for Improving the Mental Health of the Young Students}

According to the experiment in the freshmen of vocational school SCL-90 test, the results of this study show that nine factors of the experimental group and the control group have reached a significant level, indicating that the experimental group's standards of mental health are higher than that of control group, which means that the "sunshine sports" plays an important role in improving mental health of young students.

\section{Carrying out the "Sunshine Sports” Is Necessary to Psychological Health of Young Students}

With the "sunshine sports" deepened into the school, forming a good quality of personality psychology is not only an important factor in physical and mental health of contemporary youth, but also the material basis for them to become a useful person. The "sunshine sports" is a collective sport and with a certain degree of competitive, collective sports can make personality fully displayed, experience the joy of success and meet the needs of self-realization, and thus prove their ability, and enhance their self-confidence and self-esteem. Also, it can be recognized by their peers and collectively, so as to make their own good attribution, expose the lack of their own, discover their strengths, constantly revise their own knowledge and behavior, flourish their potential and strengths, correct their own shortcomings and deficiencies, which is conducive to the students in increasing self-consciousness. Thus, to participate in the "sunshine sports" is very necessary.

\section{More Young People Must Participate in the "Sunshine Sports" to Raise the Level of Mental Health}

The "sunshine sports" in Shanghai requires that, "Everyone has the project, every class has activities, every school unique”. However, by the questionnaire survey, a small number of schools are rarely involved in activities, and most of the schools involved in sports activities incompletely, because mental health in Shanghai did not significantly increased. Therefore, departments should attach importance to, for example, the school can participate in the "sunshine sports" as the performance of leader for the guidance of the relevant assessment, and increase capital investment, while increasing the diversity of the "sunshine sports", fun and attract more students out of class, out of the network, adding to sports activities to form a wave of youth physical activity. Instead, slogans and conscientious are very difficult to attract more students to participate in sports and difficult to improve adolescent mental health status, too. 


\section{References}

Cheng, Y., \& Yu, L. (2007). Network induced psychological problems of adolescents and problem behavior on the analysis. Education, 12, 35-37. (in Chinese)

Dong, H. J. (2009). Outward bound on the introduction of college physical education students and the quality of mental health movement of the experimental study of the impact (China Outstanding Master's Degree Paper Full Text Database). (in Chinese)

Marsh, H. W. (1998). Age and gender effects in physical self-concepts for adolescent elite athletes and nonathletes: A multicohort-multioccasion design. Journal of Sport and Exercise Psychology, 20, 237-259

Ministry of Education. (2006, December). Millions of students in the decision of the sun sports. General Administration of Sport, Communist Youth League Central Committee. (in Chinese)

Yin, Z. G. (2009). Under sunlight sports background young people psychologically healthy investigation and study (China Outstanding Master's Degree Paper Full Text Database). (in Chinese) 